\title{
Exposure to the Covid-19 pandemic and generosity ${ }^{1}$
}

\author{
P. Brañas-Garza², D. Jorrat² ${ }^{2}$ A. Alfonso ${ }^{2,3}$, A.M. Espín ${ }^{2,4}$, T. García Muñoz ${ }^{4}$ J. Kováŕík ${ }^{5,6,7}$
}

\begin{abstract}
We report data from an online experiment, which allow us to study whether generosity has changed during the early Covid-19 pandemic. We have gathered data from Spanish participants over a six-day period in which Covid-19-associated deaths in Spain, one of the most affected countries, increased fourfold. In our experiment, participants could donate a fraction of a €100 prize to a charity. Our data are particularly rich in the age distribution and we complement them with daily public information about the Covid-19-related deaths, infections, and hospital admissions. We find that donations decreased in the period under study and scale down with the public information about the life and health impact of the pandemic. The effect is particularly pronounced among older subjects. Our analysis of the mechanisms behind the detected decrease in solidarity highlights the key—but independent-role of expectations about others' behavior, perceived mortality risk, and (alarming) information in behavioral adaptation.
\end{abstract}

Keywords: Generosity, Covid-19, Experiments, Social Preferences

\footnotetext{
${ }^{1}$ Financial support from MINECO-FEDER (PGC2018-093506-B-I00, ECO 2015-64467-R, ECO 201566027-P, PID2019-106146GB-I00, and PID2019-108718GB-I00), Excelencia-Andalucía (PY18-FR0007), the Basque government (IT1336-19), and GAČR (17-25222S) is gratefully acknowledged. Antonio Espín acknowledges funding from the European Union's Horizon 2020 research and innovation program under the Marie Skłodowska-Curie grant agreement No. 754446 and UGR Research and Knowledge Transfer Fund - Athenea3i.

${ }^{2}$ Loyola Behavioral Lab, Universidad Loyola Andalucía, Spain.

${ }^{3}$ Universidad Pablo de Olavide, Sevilla, Spain.

${ }^{4}$ Universidad de Granada, Spain.

${ }^{5}$ Universidad del País Vasco, Spain.

${ }^{6}$ CERGE-EI, Prague, Czech Republic.

${ }^{7}$ Faculty of Arts, University of West Bohemia, Pilsen, Czech Republic.
} 


\section{INTRODUCTION}

Fairness, generosity, and other manifestations of human prosociality are fundamental features of well-functioning societies, with important consequences in virtually all spheres of human socioeconomic life. Their role is particularly relevant in times of hardship, when the reconstruction of economic, social, and political order requires people to stick together and cooperate. Hence, how generosity and social cohesion evolve during crises—be they economic, social, or healthrelated—is a fundamental question.

The 2020 Covid-19 pandemic is arguably an instance of such a crisis. It represents one of the most serious global crisis after the World War II, affecting the life of virtually all people across the globe and generating large human, economic, and social costs. From a behavioral perspective, the pandemic can be viewed as a collective action problem in which the success of the group-a region, a country, or the whole humanity-depends on individual actions. Indeed, leaders continuously appeal to individual responsibility to combat the pandemic by asking people to stay at home, avoid crowds, wear face masks, not to overconsume certain goods etc. (WHO, 2020). Most of these behaviors involve a tradeoff between individual and collective interests, eventually opening room for the "tragedy of the commons" (Hardin, 1968; Ostrom, 1990). Although governments have attempted to prevent some collective action issues by imposing formal restrictions and sanctions, cooperation and norm adherence-and thus the ability of societies to cope with the pandemic — still largely rely on individual, voluntary decisions. Not surprisingly, scholars across the behavioral sciences call to emphasize the impact of one's own actions on the well-being of others while designing and communicating public health campaigns (Van Bavel et al., 2020) and many campaigns in fact do so. But, what fraction of the population lacks the intrinsic motivation to cooperate during a pandemic? Does the fraction adapt endogenously to the pandemic environment? Is the fraction of prosocially motivated individuals smaller or larger compared to non-pandemic times? These questions have important policy implications since they point to a potential endogeneity problem. Policies appealing to other-regarding concerns might result ineffective and even counterproductive if they do not account for the impact of the pandemic on prosociality. 
Along these lines, there is an ongoing public debate about how the pandemic environment affects people's social behavior. Together with signs of increased solidarity (e.g., people hand-making masks for others, looking out for the most vulnerable), we have observed signs of selfishness and antisocial behavior. Many have broken confinement, hoarded essential goods, or exhibited hostile behaviors toward "out-group” members. Nevertheless, since we cannot effectively track the behavior of most people and reputation is often at stake due to the public nature of many actions (Fehr and Fischbacher, 2003; Rand and Nowak, 2013), one cannot make precise inferences about the impact of the pandemic on "pure" prosociality within and across populations on basis of mere observation and such anecdotal evidence.

In this study, we report data from an online experiment, which allow us to study whether human generosity has changed during the early Covid-19 pandemic. The experiment was conducted during in March 2020 in Andalusia, the most populated region in Spain; one of the countries most affected by Covid-19. The experiment started six days after the total lockdown of the country and lasted for six days. On day 1 of our experiment, there were 17,980 confirmed cases of contagion and 982 deaths in Spain, while these figures increased to 47,610 and 3,434 on day 6 (see Figure1). This day Spain surpassed China (where the pandemic originated) in number of victims.

The objective of this study is threefold. First, we study how the exposure to the Covid-19 threat, associated to home confinement and social distancing measures as well as other societal and economic consequences, affects human generosity.

Second, since behavior might change for many reasons, we discriminate among alternative mechanisms, through which the Covid-19 pandemic might influence generosity. For example, people may adapt their intrinsic social concerns endogenously to the new conditions (Diamond, 2005; Ostrom et al., 1999), they might be more/less generous because they expect others to be so (Nettle and Saxe 2020), or both. Hence, both social preferences and expectations may mediate the behavioral change.

Third, another question concerns the triggering factors behind any effect. The Covid-19 threat exerts strongly heterogeneous and clearly separable effects on the health and mortality of different population strata, imposing differing incentives for public cooperation and norm adherence across 
people. Age and gender are particularly relevant in case of Covid-19: mortality rates are about ten times higher for people over than under the age of 40 and twofold higher for males both worldwide (WHO, 2020) and in Spain (MSCBS, 2020). During the days preceding our experiment and the days of the experiment, all the media in Spain reported the official information about the pandemic continuously and most conversations centered on it. The situation of the elderly was at the center of the public debate. Hence, we believe that it is virtually impossible for any of our participants to be unaware of the severity and evolution of the situation, including the vulnerability of the elderly. In contrast, although the mortality rates were roughly twofold higher for males, the role of gender was largely absent in the media and official communications. Such information asymmetry between these factors provides an experiment-like variation in the intensity of both mortality risk (that varies across age groups and genders) and mortality cues (more salient for age vs. gender). We thus ask whether generosity changes differently across people depending on the true vs. perceived Covid-19-associated mortality. ${ }^{8}$

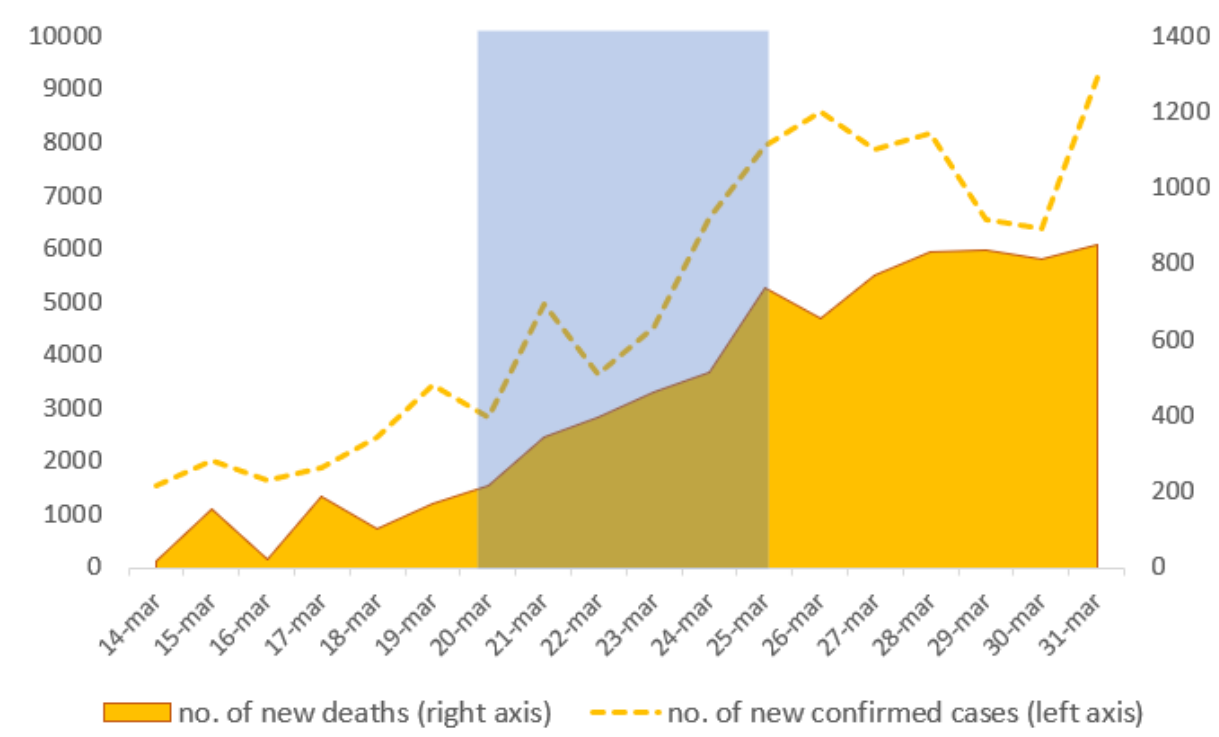

Fig. 1. Number of new Covid-19 cases and associated deaths in Spain from the date of lockdown (14 March) to 31 March 2020. The days on which the experiment took place are highlighted (shaded area; March 20-25). At the start of the experiment, new deaths averaged about 200/day, and new contagions about 3,000/day. At the end of the experiment, new deaths and new cases averaged more than 700/day and 7,000/day, respectively. Data source: Spanish Ministry of Health (MSCBS, 2020).

\footnotetext{
${ }^{8}$ This links our study to theories in social psychology and human behavioral ecology that analyze the impact of mortality cues on preferences and behaviors (Griskevicius et al., 2011, Amir et al., 2018; Pepper and Nettle, 2017; McAdams et al., 2019).
} 
To these aims, we elicit experimentally subjects' donations to charity, their expectations about the donations of others, and their self-reported social concerns (see Section 2). We further complement the experimental data with the official Spanish statistics regarding the number of deaths, infected people, and patients at intensive care units (MSCBS, 2020). We employ the latter data as measures of the intensity of the Covid-19 threat faced by our subjects.

Despite the relatively short period under study, we detect that higher exposure to the Covid-19 threat is associated with lower donations, particularly among older participants. Gender does not predict the effect of exposure on donations. Expectations about others' donations also decrease in the period under study and partially explain the effect of exposure on donations. Nevertheless, accounting for the expectations about others' giving behavior does not eliminate the age (interaction) effect. Self-reported social preferences, however, do not follow the decreasing tendency of the actual and expected donations. All these results are reinforced if, instead of the participation day, we employ the public information about the number of new deaths, infected people, and patients at intensive care units. Hence, public information plays an key role in the detected behavioral change.

The arguments in the scientific literature regarding how social behavior or social cohesion adapt to negative shocks go in both directions. The competition for scarcer resources in many such situations suggests that people might be less prosocial (Hardin, 1968; Dietz, 2003; Diamond, 2005; Gleditsch, 1998), whereas adversarial events might create a “common enemy” effect, thus increasing cooperation and sharing (Diamond, 2005; Ostrom et al., 1999; Henrich and Henrich, 2007; Dugatkin and Mesterton-Gibbons, 1996). The evidence supports both hypotheses (e.g. Brancati, 2007; Eckel et al., 2009; Scheffran et al., 2012; Hsiang et al., 2013; Bauer et al., 2016; Calo-Blanco et al., 2017). Hence, previous literature is inconclusive in this respect. In addition, these issues were mostly studied using aggregate data suitable to study longer-term adjustment and typically before and after the shock or only after the shock, while how prosociality adapts at the micro-level and gradually during a negative shock itself is understudied.

Naturally, the Covid-19 pandemic has already stimulated other studies. For example, Bartos et al. (2020) report that the pandemic has increased hostility toward foreigners and Bilancini et al. 
(2020) find no effect of norm-based interventions on individual pandemic response. The decreased generosity detected in our study might partially explain these results. In a more closely related study, Shachat et al. (2020) analyze how several social behaviors, beyond other economic preferences, changed across time in Wuhan, China. They compare pre-epidemic data with data gathered in five points in time covering six weeks after the city’s lockdown. Although their results suggest a long-term increase in prosociality along with the exposure to the pandemic, they also report a decrease (particularly, in trust) in the immediate aftermath of the Wuhan lockdown. While our results are in line with the latter evidence, all these findings indicate that social behavior adapts following a complex pattern and that both short-term and long-term dynamics need to be considered separately.

Our data provide one step toward the estimation of the extent to which people are willing to comply with the norms necessary to combat the Covid-19 pandemic and how this willingness evolves over a time. Such data are critical for a correct calibration of infectious diseases models (Weston et al., 2018). Overall, our results as well as the cited evidence suggest that these models and the policies combating the pandemic might be miscalibrated if they do not account for the extent to which people are intrinsically motived to act prosocially and how this motivation adapts to the pandemic environment. ${ }^{9}$ The data generated in our experiment is an example of how experimental and behavioral economics can inform epidemiology and other fields while modeling disease transmission and policy makers while designing prevention policies combating the Covid19 and other pandemics.

The remainder of the paper is organized in three sections. Section 2 describes the experimental design and procedures, Section 3 presents the results, and the last section concludes.

\footnotetext{
${ }^{9}$ For example, the Imperial College model (Ferguson et al., 2020) that have guided the prevention policy in the UK while combating the Covid-19 pandemic and inspired policies of other countries assumes among other things that $25 \%$ of older people will not comply with social distancing. This figure is assumed without any empirical basis and the parameter is held constant in their model. This may seriously misguide policy recommendations.
} 


\section{EXPERIMENTAL DESIGN AND PROCEDURES}

\section{Recruitment and Sample}

We invited 103 university students of an Andalusian university to participate in an online experiment. The students were encouraged and incentivized to recruit further participants, with the objective of obtaining a richer subject pool in terms of age, non-student status, and other characteristics. Gender balance and homogeneity across different ages was explicitly encouraged. Neither the participation nor recruitment were compulsory. Those who decided to participate ( $n=85)$ recruited other participants from Andalusia, other Spanish regions, or outside Spain (see Appendix A1 for details).

The experiment focused on the region of Andalusia, but this not prevented participation of people from outside Andalusia (people from other parts of Spain, $n=191$, and from other countries, $n=20$ ). Given that the non-Andalusian participants came from many different locations and that their numbers within locations were small and unevenly distributed (see Appendix A2), they were excluded from the analyses.

Our procedures resulted in a final sample of 969 Andalusian participants (mean age $=35.10$; $\mathrm{SD}=17.16)$ of which $55 \%$ were females. Our sample allows us to obtain small effects $(r=0.09)$ with $80 \%$ power and alpha $=0.05$. The sample sizes for each day from March 20-25 were 163, 188, 139, 92, 129, and 258, respectively. Since the observations were not uniformly distributed across the six days of the experiment, we conservatively split the sample in half into two periods to ensure the right balance in our main analysis: March 20-22 $(n=490)$ and March 23-25 $(n=479)$. This allows us to obtain a relatively balanced sample between both three-day periods in terms of sample size, age, education and gender (see Appendix A2 for details).

All participants signed an informed consent and the data were anonymized in accordance with the Spanish Law on Personal Data Protection 3/2018. There are no participants under 16 year old. ${ }^{10}$

\footnotetext{
10 Those with 16 and 17 year old (sixteen in our sample) can give their consent without asking their parents (Article 8 and Recitals 38 and 58 of the Directive 95/46/EC).
} 
The main purpose of this experiment was to gather data for teaching purposes. To study the Covid19 was not the main goal. However, the home confinement was the reason to run the experiment online in order to have data to discuss in class.

\section{Experimental tasks}

As is standard in economic experiments, we used monetary incentives. We informed all participants that they would participate in a lottery in which two participants would earn €100. The identity and behavior of each participant were kept anonymous to prevent reputational concerns that could affect behavior. Experimental earnings (from decisions during the experiment) were converted into tickets for the two €100-lotteries.

The entire experimental setting consisted of several tasks (see Instructions for details ${ }^{11}$ and Appendix A3 for the description of the experimental setting). In this paper, we focus on three behavioral measures elicited in the experiment:

(A) Donations. We elicit answers to the following question: "If you win the $100 €$ prize, would you like to donate a fraction to an NGO?" People could choose any donation between $0 \%$ and $100 \%$, in $10 \%$ increments. This question was incentive compatible and implemented without deceiving participants.

(B) Expected others' donations (not incentivized). Using the same question format, participants were asked to report their answer to the question "How much money do you think the other participants will donate to the NGO?”. This variable also ranges from 0 to $100 \%$, in $10 \%$ increments. In line with previous evidence (e.g. Brañas-Garza et al., 2017), expected donations are lower than real donations (matched-pairs t-test, $p<0.001$ ), although they are strongly correlated (Pearson's $r=0.636, p<0.001$ ). That is, people expect others to be less generous than themselves and those who give more expect others to give more.

(C) Self-reported solidarity and envy. These social preference variables measure people's self-reported aversion to advantageous inequality, often referred to as "compassion" or

\footnotetext{
${ }^{11}$ Original instructions in Spanish and the translation to English are available here: https://repositorio.uloyola.es/handle/20.500.12412/2250.
} 
“guilt”, and disadvantageous inequality (Fehr and Schmidt, 1999), respectively. Using a Likert scale, we asked participants their agreement with the statement "I do not care about how much money I have; what concerns me is that there are people who have less (more) money than I have” (proposed in Espín et al. 2018). As in Espín et al. (2018), these measures predict donations (see Table A2), the participants report higher SR-solidarity than SR-envy (matched-pairs t-test, $p<0.001$ ), and the two measures are only weakly correlated (Pearson's $r=0.117, p<0.001$ ).

We additionally elicited certain socio-demographic variables, including gender, age, education, and province of residence. These variables were employed in the regression analysis. Appendix A2 and A3 provide an extensive description of the sample and the most relevant variables of this study.

Subjects further participated in the following experimental tasks: the Cognitive Reflection Test (Frederick, 2005; Toplak et al., 2014), Risk Preferences (Holt and Laury, 2002), Time Preferences (Coller and Willians, 1999; Martin et. al., 2019), Stag Hunt Game (Skyrms, 2004) and the Big-5 personality inventory (Rammstedt and John, 2007). These data are not employed in this study.

\section{Other measures}

We complement our experimental data with the official Spanish statistics regarding the daily number of deaths, infected people, and patients at intensive care units (MSCBS, 2020). Since these data were released every day at 9pm and immediately reported by virtually all Spanish media, we analyze whether the official figures from one day affect the next-day donations in our experiment. In our analysis, we interpret these figures as the public information that people perceived regarding the intensity of the pandemic threat.

\section{RESULTS}

\section{Giving}

Figure 2 shows the donations in our experiment, disaggregated by age and gender (panels $\mathrm{A}$ and B). Panel A plots the average donations on March 20-22 vs. March 23-25 for participants older or younger than 40 years old (the entire distributions are shown in Figures A2 and A3 in the 
Appendix, where we also compare our data to Engel's (2011) meta-analysis). We can see that younger people are more selfish overall. Nevertheless, while their donations do not seem to be affected by the Covid-19 exposure, older participants become considerably more selfish in the second half of the experiment. Panel B displays the donations disaggregated by gender (see also Figure A3 in the Appendix). We do not observe any difference between males and females, and the exposure to Covid-19 does not seem to impact males and females differently. Both genders decrease their donations slightly and in similar magnitudes.

To analyze formally whether subjects' behavior changes with the intensity of the exposure to the Covid-19 threat, model 1a in Table 1 regresses participants' donations on a dummy for March 23-25 (vs. March 20-22, reflecting intensity of exposure), age (taking logs to reduce right skewness), and a male dummy, using linear regression model with robust standard errors.

This main specification confirms that the effect of the participation day on donations is negative and statistically significant, with an estimated reduction of 6.0\% in donations from March 20-22 to March 23-25 (SE = 2.1\%, $p=0.006)$. Moreover, in line with previous evidence (Engel, 2011), age yields a significantly positive effect on donations (coef $=0.140, p<0.001$ ); gender is never significant $(p>0.8)$. 


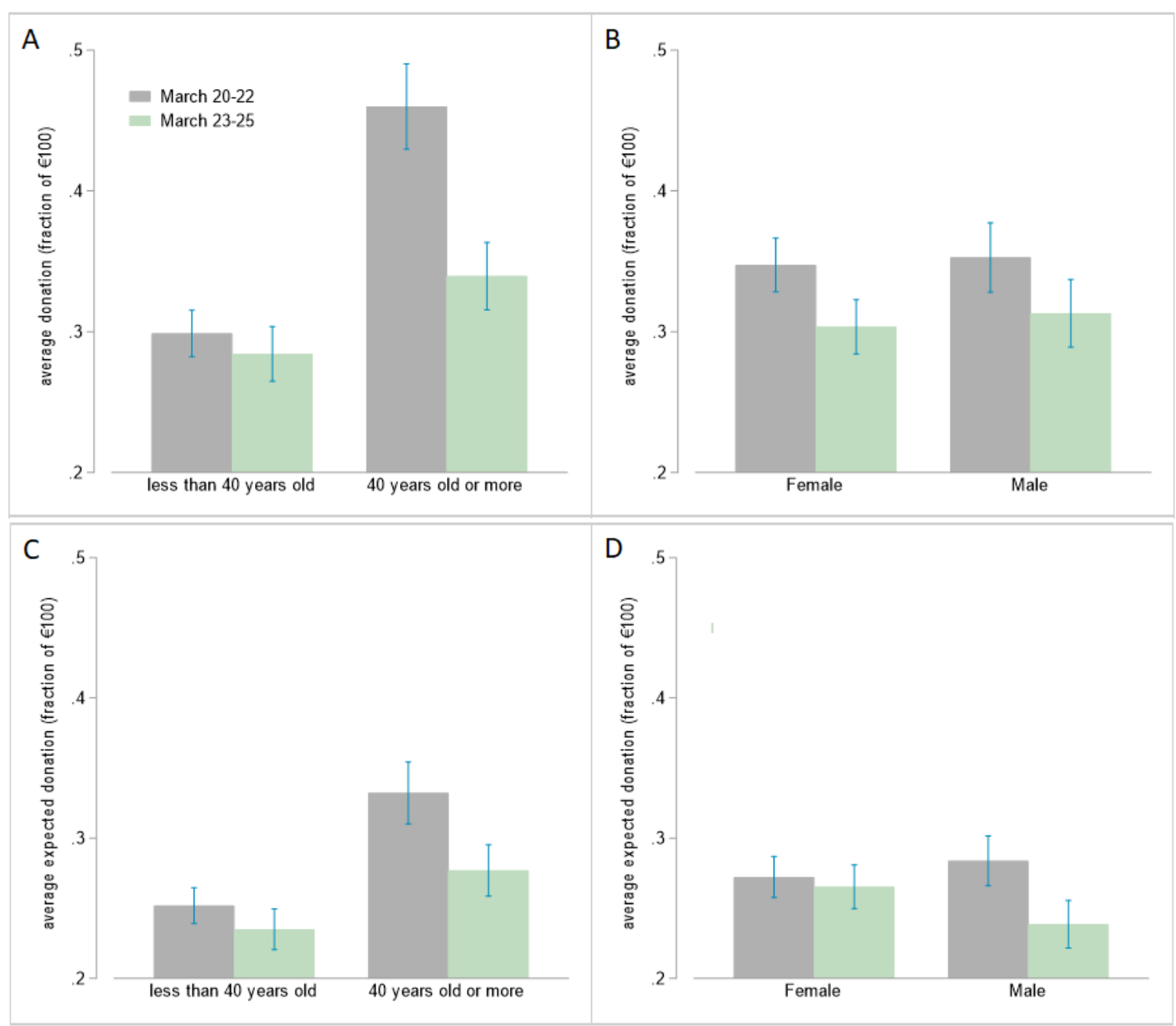

Figure 2. Actual and expected donations on March 20-22 vs. March 23-25. Panels (A) and (B) display average donations broken down by age groups ( $<40$ years old and $\geq 40$ years old) and gender, respectively. Panels (C) and (D) display average expected donations broken down by age groups and gender, respectively. Error bars represent SEM. Error bars represent SEM.

To test whether the effect is stronger for older or male participants, model $1 \mathrm{~b}$ in Table 1 introduces the interactions day $\times$ age and day $\times$ gender. Consistent with Panel A (Figure 2), the day $\times$ age interaction is negative and significant (coef $=-0.097, p=0.048$ ), indicating a stronger negative effect for older participants. Wald tests on the model estimates suggest no effect of exposure on donations for people aged below 29, and a negative significant impact for age $\geq 29$, using $p=$ 0.05. Gender, however, does not moderate the decrease in donations; the interactions day $\times$ gender and day $\times$ age $\times$ gender (model 1c) never result significant $(p>0.4)$.

We thus conclude that older participants become more selfish due to the exogenous increase in exposure to Covid-19. However, we find no differential effect by gender. In the following, we test whether subjects' expectations about others' donations and/or their self-reported social concerns explain the detected decline in donations and the differential age effect. 


\section{Expected giving}

Expected donations (labeled as Expectations in Table 1) report how much our participants expected others to donate. Panels C-D in Figure 2 illustrate the effect of exposure on these expectations from March 20-22 to March 23-25 (see also Figure A4 in the Appendix). There is an overall decline in the expectations in the second half of the experiment. Notably, the effect is stronger for participants above 40 (Panel C) and males (Panel D).

Models 2a-c reproduce models 1a-c using the expected donations as the dependent variable. The estimates corroborate that higher exposure is associated with lower expected donations in model 2a $($ coef $=-3.4 \%, S E=1.6 \%, p=0.036)$. However, although none of the interactions are significant in models $2 \mathrm{~b}$ and $2 \mathrm{c}(p>0.2)$, Wald tests on the estimates of model $2 \mathrm{~b}$ suggest no effect of the exposure for age $<29$, while we again accept a negative significant impact for age $\geq$ 29 at 5\%. Regarding gender, the Wald tests on model estimates suggest no effect for female while we find a negative significant effect for male, as suggested by Panel 2D.

Thus, expected donations decrease with exposure along with the actual giving. This suggests that participants might reduce their donations because they expect others to do so (Nettle and Saxe 2020). To explore this hypothesis, models 1a-1c in Table A2 (Appendix) repeat the analysis of giving to charity from Table 1 introducing the expectations as an additional regressor. This model confirms the above hypothesis: the estimated effect of participation day is reduced from $6.0 \%$ to $3.2 \%$ and becomes only marginally significant once we control for expected donations $(p=0.068)$ 


\begin{tabular}{|c|c|c|c|c|c|c|c|c|c|c|c|c|}
\hline & (1a) & (1b) & (1c) & (2a) & $(2 \mathrm{~b})$ & (2c) & (3a) & (3b) & (3c) & (4a) & $(4 \mathrm{~b})$ & (4c) \\
\hline & Donation & Donation & Donation & Expectations & Expectations & Expectations & Solidarity & Solidarity & Solidarity & Envy & Envy & Envy \\
\hline mar23-25 & $\begin{array}{c}-0.060 * * * \\
(0.022)\end{array}$ & $\begin{array}{c}0.273 \\
(0.167)\end{array}$ & $\begin{array}{c}0.150 \\
(0.210)\end{array}$ & $\begin{array}{c}-0.034^{* *} \\
(0.016)\end{array}$ & $\begin{array}{c}0.107 \\
(0.122)\end{array}$ & $\begin{array}{c}0.077 \\
(0.159)\end{array}$ & $\begin{array}{c}0.029 \\
(0.020)\end{array}$ & $\begin{array}{c}0.212 \\
(0.158)\end{array}$ & $\begin{array}{c}0.076 \\
(0.208)\end{array}$ & $\begin{array}{c}0.001 \\
(0.018)\end{array}$ & $\begin{array}{l}-0.025 \\
(0.138)\end{array}$ & $\begin{array}{c}0.071 \\
(0.182)\end{array}$ \\
\hline male & $\begin{array}{c}0.003 \\
(0.022)\end{array}$ & $\begin{array}{c}-0.000 \\
(0.030)\end{array}$ & $\begin{array}{l}-0.084 \\
(0.239)\end{array}$ & $\begin{array}{c}-0.010 \\
(0.016)\end{array}$ & $\begin{array}{c}0.009 \\
(0.023)\end{array}$ & $\begin{array}{c}0.033 \\
(0.171)\end{array}$ & $\begin{array}{c}-0.055^{* * *} \\
(0.020)\end{array}$ & $\begin{array}{c}-0.081 * * * \\
(0.027)\end{array}$ & $\begin{array}{c}-0.137 \\
(0.216)\end{array}$ & $\begin{array}{c}0.016 \\
(0.018)\end{array}$ & $\begin{array}{c}-0.003 \\
(0.025)\end{array}$ & $\begin{array}{l}0.328 * \\
(0.193)\end{array}$ \\
\hline l(age) & $\begin{array}{c}0.140 * * * \\
(0.025)\end{array}$ & $\begin{array}{c}0.189 * * * \\
(0.035)\end{array}$ & $\begin{array}{c}0.179 * * * \\
(0.046)\end{array}$ & $\begin{array}{c}0.078 * * * \\
(0.018)\end{array}$ & $\begin{array}{c}0.096 * * * \\
(0.025)\end{array}$ & $\begin{array}{c}0.099 * * * \\
(0.032)\end{array}$ & $\begin{array}{c}0.099 * * * \\
(0.023)\end{array}$ & $\begin{array}{c}0.129 * * * \\
(0.032)\end{array}$ & $\begin{array}{c}0.122 * * * \\
(0.043)\end{array}$ & $\begin{array}{l}-0.013 \\
(0.020)\end{array}$ & $\begin{array}{l}-0.014 \\
(0.029)\end{array}$ & $\begin{array}{c}0.028 \\
(0.041)\end{array}$ \\
\hline mar23-25 × l(age) & & $\begin{array}{c}-0.097 * * \\
(0.049)\end{array}$ & $\begin{array}{c}-0.062 \\
(0.063)\end{array}$ & & $\begin{array}{l}-0.036 \\
(0.036)\end{array}$ & $\begin{array}{c}-0.027 \\
(0.047)\end{array}$ & & $\begin{array}{c}-0.060 \\
(0.046)\end{array}$ & $\begin{array}{c}-0.021 \\
(0.060)\end{array}$ & & $\begin{array}{c}0.002 \\
(0.040)\end{array}$ & $\begin{array}{l}-0.026 \\
(0.054)\end{array}$ \\
\hline mar23-25 $\times$ male & & $\begin{array}{c}0.007 \\
(0.043)\end{array}$ & $\begin{array}{c}0.282 \\
(0.342)\end{array}$ & & $\begin{array}{l}-0.037 \\
(0.032)\end{array}$ & $\begin{array}{c}0.027 \\
(0.247)\end{array}$ & & $\begin{array}{c}0.052 \\
(0.040)\end{array}$ & $\begin{array}{c}0.354 \\
(0.317)\end{array}$ & & $\begin{array}{c}0.038 \\
(0.036)\end{array}$ & $\begin{array}{l}-0.193 \\
(0.281)\end{array}$ \\
\hline male $\times$ l(age) & & & $\begin{array}{c}0.025 \\
(0.072)\end{array}$ & & & $\begin{array}{l}-0.007 \\
(0.051)\end{array}$ & & & $\begin{array}{c}0.017 \\
(0.064)\end{array}$ & & & $\begin{array}{l}-0.098^{*} \\
(0.056)\end{array}$ \\
\hline mar23-25 $\times$ l (age $) \times$ male & & & $\begin{array}{l}-0.079 \\
(0.100)\end{array}$ & & & $\begin{array}{l}-0.018 \\
(0.072)\end{array}$ & & & $\begin{array}{l}-0.087 \\
(0.092)\end{array}$ & & & $\begin{array}{c}0.069 \\
(0.081)\end{array}$ \\
\hline Constant & $\begin{array}{l}-0.127 \\
(0.082)\end{array}$ & $\begin{array}{c}-0.291^{* *} \\
(0.116)\end{array}$ & $\begin{array}{l}-0.255^{*} \\
(0.150)\end{array}$ & $\begin{array}{c}0.018 \\
(0.060)\end{array}$ & $\begin{array}{l}-0.052 \\
(0.084)\end{array}$ & $\begin{array}{l}-0.062 \\
(0.105)\end{array}$ & $\begin{array}{l}0.153^{*} \\
(0.078)\end{array}$ & $\begin{array}{c}0.063 \\
(0.108)\end{array}$ & $\begin{array}{c}0.087 \\
(0.145)\end{array}$ & $\begin{array}{c}0.283^{* * *} \\
(0.068)\end{array}$ & $\begin{array}{c}0.295^{* * *} \\
(0.097)\end{array}$ & $\begin{array}{c}0.154 \\
(0.136)\end{array}$ \\
\hline Observations & 969 & 969 & 969 & 969 & 969 & 969 & 969 & 969 & 969 & 969 & 969 & 969 \\
\hline Adjusted R-squared & 0.036 & 0.038 & 0.037 & 0.019 & 0.019 & 0.017 & 0.028 & 0.029 & 0.029 & -0.002 & -0.003 & -0.001 \\
\hline Province FE & No & No & No & No & No & No & No & No & No & No & No & No \\
\hline F test & $11.85 * * *$ & $7.65 * * *$ & $5.74 * * *$ & $7.13 * * *$ & $4.61 * * *$ & $3.36 * * *$ & $10.10 * *$ & $6.85^{* * *}$ & $5.13^{* * *}$ & 0.347 & 0.454 & 0.855 \\
\hline
\end{tabular}

Table 1. OLS estimates: the impact of Covid-19 exposure on actual donations. The variable mar23-25 represents the increasing exposure to the Covid-19 threat as a dummy variable taking the value of 1 if the participation was during March 23 to March 25 and 0 if it was during March 20 to March 22. In column 1a we regress the outcome variable on the participation day dummy; in column $1 \mathrm{~b}$ we add interactions of participation day with $\log (\mathrm{age})$ and with gender; and in column 1c we add the three-way interaction of participation day $\times$ log(age) $\times$ gender. Columns 2a to 2c repeat the specifications of columns 1a to 1c for expected donations (beliefs). Columns 3a to 3c and 4a to 4c do similarly for self-reported solidarity and envy, respectively. All regressions include a male dummy variable and age in logs. 
An equivalent structural equations model corroborates that this reduction is significant (indirect effect $=-2.8 \%, p=0.036$; Figure A7, Appendix) and suggests that $47.3 \%$ of the effect of exposure on donations is mediated by participants' beliefs about others' donations.

In a similar analysis using the model with two-way interactions, ${ }^{12}$ the interaction day $\times a g e$ is slightly reduced and becomes marginally significant if we control for expectations or the interaction day $\times$ expectations ( $p=0.087$ and $p=0.067$, resp.). However, since these reductions are not significant (Wald test, $p>0.3$ ) and the three-way interaction day $\times$ age $\times$ expectations is also non-significant, we conclude that the effect of age is only partially explained by the expected donations. Indeed, according to the Wald tests performed on the estimates from model 1b in Table A2, the negative impact of the exposure on Covid-19 remains significant at $5 \%$ for people aged over 30, even if we control for the subjects’ expectations.

\section{Self-reported inequity aversion}

Last, we explore how both SR-solidarity and SR-envy vary during the confinement. Panels A and B in Figure 3 plot the average solidarity, decomposed by age and gender groups (see also Figure A5 in the Appendix). The figures suggests that young participants and men declare to be somewhat less concerned about other people having less that themselves and both groups increase their solidarity slightly with the exposure (but the latter effect is insignificant in the regressions below). Regarding envy, Panels $\mathrm{C}$ and $\mathrm{D}$ in Figure 3 suggest that there are no remarkable differences between females and males or age groups as well as between March 20-22 and March 23-25 (see also Figure A6 in the Appendix).

Models 3a to 4c in Table 1 estimate whether self-reported social preferences (solidarity and envy) also change with higher threat exposure. The analysis reveals that none of the main or interaction effects of these variables is ever significant at less than $10 \%$. Hence, self-reported social preferences do not seem to change along with the exposure.

\footnotetext{
${ }^{12}$ Not reported here. See the working paper for details: https://psyarxiv.com/6ktuz
} 


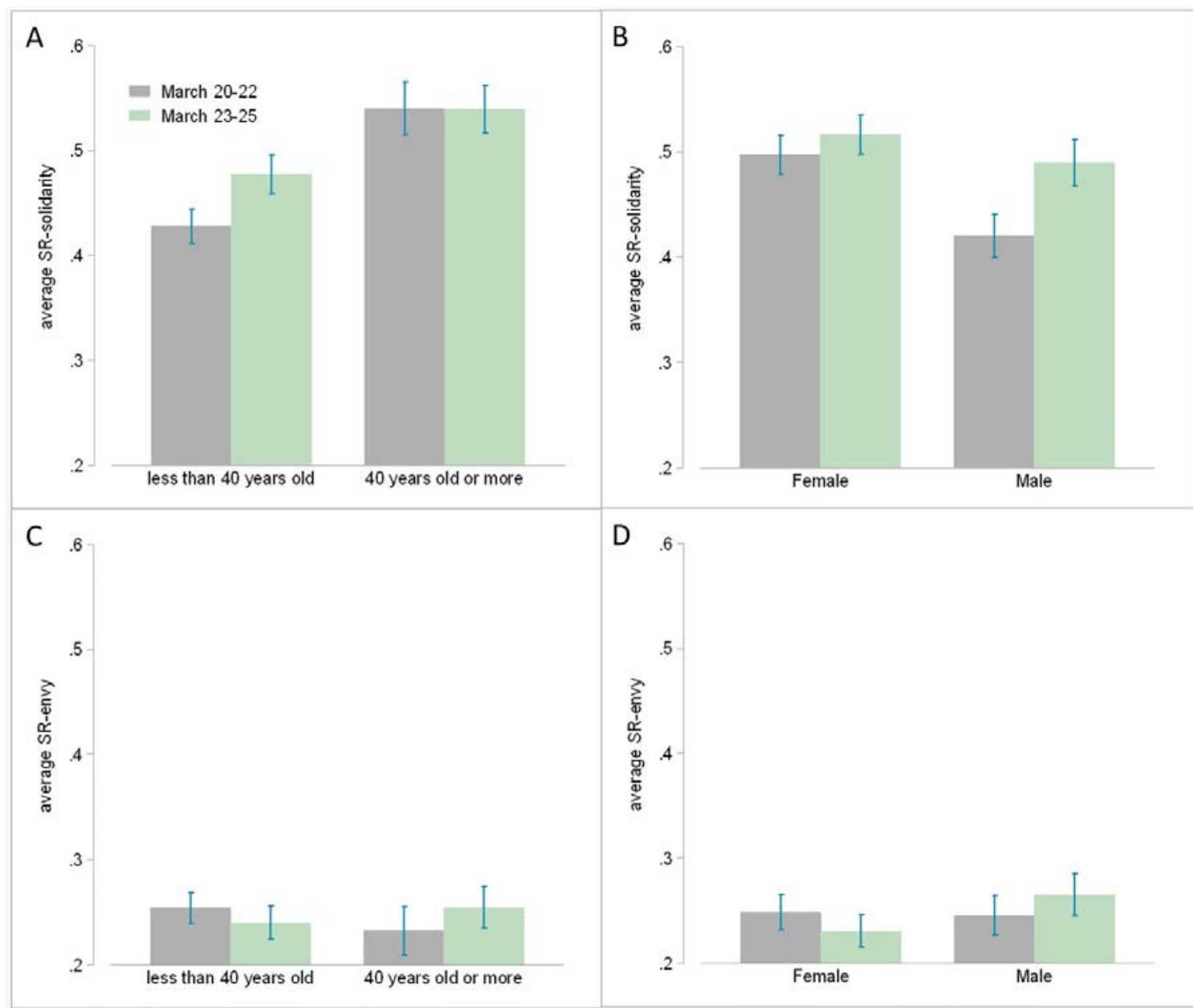

Figure 3. Self-reported social preferences on March 20-22 vs. March 23-25. Panels (A) and (B) display average SR-solidarity broken down for age groups $(<40$ and $\geq 40)$ and gender, respectively. Panels $(C)$ and (D) display average SR-envy broken down for age groups and gender, respectively. Error bars represent SEM.

Finally, we use self-reported solidarity and envy as explanatory variables for giving in models 2a-2c in Table A2 (Appendix). As mentioned, solidarity and envy are significant predictors of donations in our experiment: those who self-report higher solidarity and lower envy donate more $(p<0.001)$. The moderation effect of age on giving is robust to controlling for self-reported solidarity and envy though. Model 2a indicates that the effect of participation day remains negative and statistically significant and model $2 \mathrm{~b}$ reveals that the negative effect of the interaction day $\times$ age remains negative and marginally significant. The Wald test suggests no effect of exposure for age $<24$ and a negative significant impact for age $\geq 24$ at conventional $5 \%$ if we control for the self-reported social preferences. Most importantly, since the effect of day on donations is never reduced after controlling for self-reported preferences, these findings indicate 
that the detected behavioral change and the moderation effect of age cannot be explained by selfreported social concerns.

\section{Public Information}

The above analysis studies how donations vary between the first and second halves of the experiment. However, Figure 1 shows that the number of affected and deceased people in Spain do not scale up linearly over the six days under study. Since these figures have continuously been broadcasted, they can be considered as proxies for public information regarding the intensity of exposure to Covid-19. We thus substitute the time dummies in our models with official daily data regarding the new deaths, new infected people, and new patients in intensive care units (ICU), provided by the Spanish Ministry of Health (MSCBS, 2020) and reported by Spanish media. Table 2 explores the impact of these variables on giving to charity in our experiment. As mentioned above, since these data were release every day after 9PM, we estimate the impact of the statistics reported one day earlier (one-day lag) on subjects' donations.

Independently of the measure we use as the explanatory variable, the results confirm the above findings: subjects' donations scale down with the number of new deaths, infected, and ICU admissions and the effect is mostly driven by older participants. More precisely, model 1a in Table 2 uses only deaths without the interaction l(age) $\times$ deaths, while model $1 \mathrm{~b}$ accounts for both. The estimates indicate that the effect of deaths on overall generosity is negative (coef $=-0.029$, $p=0.014$ ), but most of this effect is driven by older participants (in model $1 \mathrm{~b}$, the interaction is marginally significant; coef $=-0.053 ; p=0.065$ ). This is confirmed for the number of people infected every day (model 2a: infected, coef $=-0.002, p=0.019$; model 2b: l(age) $\times$ infected, coef $=-0.004, p=0.075$ ) and ICU admissions (model 3a: ICU, coef $=-0.037, p=0.015$; model 3b: $l($ age $) \times I C U$, coef $=-0.060, p=0.053){ }^{13}$

\footnotetext{
${ }^{13}$ Figure A8 (Appendix) illustrates graphically the effects of the three pieces of public information on the estimated donations by (log) age. Panel A corresponds to the new deaths, Panel B to infected, and Panel C to ICU admissions. Average marginal effects are plotted with the corresponding 95\% confidence intervals. In the three cases, we observe that the effects are different from zero for roughly $\log ($ age $)>3.3$, corresponding to subjects older than 30 .
} 


\begin{tabular}{|c|c|c|c|c|c|c|}
\hline & $\begin{array}{l}(1 a) \\
\text { Donations }\end{array}$ & $\begin{array}{l}(1 \mathrm{~b}) \\
\text { Donations }\end{array}$ & $\begin{array}{l}\left(2^{\mathrm{a}}\right) \\
\text { Donations }\end{array}$ & $\begin{array}{l}(2 \mathrm{~b}) \\
\text { Donations }\end{array}$ & $\begin{array}{l}\text { (3a) } \\
\text { Donations }\end{array}$ & $\begin{array}{l}\text { (3b) } \\
\text { Donations }\end{array}$ \\
\hline deaths & $\begin{array}{l}-0.029 * * \\
(0.012)\end{array}$ & $\begin{array}{l}0.152 \\
(0.097)\end{array}$ & & & & \\
\hline deaths $\times$ l(age) & & $\begin{array}{l}-0.053^{*} \\
(0.028)\end{array}$ & & & & \\
\hline infected & & & $\begin{array}{l}-0.002 * * \\
(0.001)\end{array}$ & $\begin{array}{l}0.011 \\
(0.007)\end{array}$ & & \\
\hline infected $\times$ l(age) & & & & $\begin{array}{l}-0.004 * \\
(0.002)\end{array}$ & & \\
\hline ICU & & & & & $\begin{array}{l}-0.037 * * \\
(0.015)\end{array}$ & $\begin{array}{l}0.203^{*} \\
(0.123)\end{array}$ \\
\hline ICU $\times$ l(age $)$ & & & & & & $\begin{array}{l}-0.069 * \\
(0.036)\end{array}$ \\
\hline male & $\begin{array}{l}0.003 \\
(0.022)\end{array}$ & $\begin{array}{l}0.003 \\
(0.022)\end{array}$ & $\begin{array}{l}0.003 \\
(0.022)\end{array}$ & $\begin{array}{l}0.003 \\
(0.022)\end{array}$ & $\begin{array}{l}0.003 \\
(0.022)\end{array}$ & $\begin{array}{l}0.003 \\
(0.022)\end{array}$ \\
\hline l(age) & $\begin{array}{l}0.138 * * * \\
(0.025)\end{array}$ & $\begin{array}{l}0.250 * * * \\
(0.066)\end{array}$ & $\begin{array}{l}0.138 * * * \\
(0.025)\end{array}$ & $\begin{array}{l}0.299 * * * \\
(0.094)\end{array}$ & $\begin{array}{l}0.138 * * * \\
(0.025)\end{array}$ & $\begin{array}{l}0.290 * * * \\
(0.083)\end{array}$ \\
\hline Constant & $\begin{array}{l}-0.088 \\
(0.082)\end{array}$ & $\begin{array}{l}-0.470 * * \\
(0.221)\end{array}$ & $\begin{array}{l}-0.060 \\
(0.084)\end{array}$ & $\begin{array}{l}-0.611^{*} \\
(0.318)\end{array}$ & $\begin{array}{l}-0.068 \\
(0.083)\end{array}$ & $\begin{array}{l}-0.591^{* *} \\
(0.281)\end{array}$ \\
\hline Observations & 969 & 969 & 969 & 969 & 969 & 969 \\
\hline Adjusted R-squared & 0.034 & 0.036 & 0.033 & 0.036 & 0.034 & 0.037 \\
\hline Province FE & No & No & No & No & No & No \\
\hline F test & 11.27 & 9.033 & 11.13 & 8.871 & 11.22 & 9.063 \\
\hline
\end{tabular}

Table 2. OLS estimates: the impact of news on actual donations. The variables deaths, infected and ICU represents the number per thousand inhabitants of deaths, infected and patients in intensive care units (ICU), respectively. In column 1a we regress the outcome variable on the number of deaths per thousand inhabitants; in column 1b we add interactions of participation day with $\log (\mathrm{age})$. Columns $2 \mathrm{a}$ to $2 \mathrm{~b}$ repeat the specifications of columns $1 \mathrm{a}$ to $1 \mathrm{~b}$ but we regress donations on the number of infected per thousand inhabitants. Columns $3 \mathrm{a}$ to $3 \mathrm{~b}$ do similarly but we regress the outcome variable on the number of patients in ICU per thousand inhabitants. All regressions include a male dummy variable and age in logs.

In sum, higher exposure to the Covid-19 threat—as measured either by participation day or public information regarding the number of daily deaths and infected people, and patients at intensive care units—is associated with lower donations, particularly among older participants. Gender does not moderate the effect of exposure on donations. Expectations about others' donations partially explain the effect of exposure on donations but the age effect is largely orthogonal to that of the expectations.

\section{DISCUSSION}

To study how prosocial behavior responds to "slow disasters" (such as droughts, pandemics, or a gradual erosion of global climate), we analyze how giving behavior towards an unknown NGO 
changes during the early exposure to the Covid-19 pandemic in southern Spain. Although our experiment was only conducted six days during the early pandemic, people decrease their generosity significantly and the decline is more pronounced for older participants, who face higher mortality rates as they are continuously reminded in the news.

There are several interpretations for these results. For example, people might donate less over time in our experiment because they shift their solidarity toward objectives directly linked to the Covid-19 pandemic. To be able to focus on pure generosity, we did not specify which charity would receive the donations. Our participants did not know whether the donated money aimed at Covid-19 related issues. Our preferred interpretation—and the one more in line with existing literature—is that the Covid-19 threat may decrease generosity toward the "outgroup” or toward people not considered as part of the "ingroup", but increase solidarity within own social circles (Bauer et al., 2013; Phan and Airoldi, 2015). Increased out-group bias during the Covid-19 pandemics has been documented in Bartos et al. (2020). Our data cannot discriminate between these and other potential explanations, however; the reported evidence should be viewed as a starting point for the understanding of how and at what speed such adversarial events shape human behavior. Similarly, we explore behavioral change in a short time window and therefore our results need to be extended to longer-term effects or adaptation processes. Shachat et al. (2020) perform a longer time horizon analysis in Wuhan, China and find long-term increases in prosociality after a decline in the immediate aftermath of the city lockdown. Our findings are consistent with such a pattern and, together, suggest that the behavioral adaptation process may follow complex dynamics.

The findings have both theoretical and practical implications. Our data indicate that deterioration of large-scale social capital might have contributed to the collapse of societies affected by "slow disasters”, such as droughts or pandemics, and that the process can be extraordinarily fast. Such explanations have been proposed (Diamond, 1997), but data collection under controlled environments in such cases is virtually impossible. Since most challenges that humanity currently faces are of global nature and depend on collective response of large groups of unrelated individuals (Ostrom et al. 1999), we provide novel evidence with implications not only for social 
and economic post-Covid-19 recovery policies, but generally for the building of social resilience to future disasters, during which large-scale collective response is as important as in the case of the Covid-19 pandemic. Such challenges are numerous (Boyd et al., 2018).

The moderating effect of age on decreasing donations—absent for gender—points to the pivotal role of information in shaping behaviors. If further research corroborates this effect, it would enhance our understanding of how social and mass media, leaders, and gossip influence behavior, with implications for regulations targeting the media, the access of different age groups to certain information, and fake news epidemics. Since the dynamics of donations differ from those of selfreported solidarity/envy in our data, people might be unaware to what extent these factors shape their behavior. 


\section{References}

Amir, D., Jordan, M. R., and Rand, D. G. (2018). An uncertainty management perspective on longrun impacts of adversity: The influence of childhood socioeconomic status on risk, time, and social preferences. Journal of Experimental Social Psychology, 79, 217-226.

https://doi.org/10.1016/j.jesp.2018.07.014

Bartos, V, Bauer, M., Cahlikova, J., and Chytilová, Julie, Covid-19 Crisis Fuels Hostility Against Foreigners (June 2020). CESifo Working Paper No. 8309, Available at SSRN: https://ssrn.com/abstract=3618833.

Bauer, M., Blattman, C., Chytilová, J., Henrich, J., Miguel, E., and Mitts, T. (2016). Can War Foster Cooperation? Journal of Economic Perspectives, 30(3), 249-274. https://doi.org/10.1257/jep.30.3.249

Bauer, M., Cassar, A., Chytilová, J., and Henrich, J. (2013). War’s Enduring Effects on the Development of Egalitarian Motivations and In-Group Biases. Psychological Science, 25(1), 47-57. https://doi.org/10.1177/0956797613493444

Bilancini, E., Boncinelli, L., Capraro, V., Celadin, T., \& Di Paolo, R. (2020). The effect of normbased messages on reading and understanding COVID-19 pandemic response governmental rules. arXiv preprint arXiv:2005.03998.

Boyd, R., Richerson, P. J., Meinzen-Dick, R., De Moor, T., Jackson, M. O., Gjerde, K. M., HardenDavies, H., Frischmann, B. M., Madison, M. J., Strandburg, K. J., McLean, A. R., and Dye, C. (2018). Tragedy revisited. Science, 362(6420), 1236-1241. https://doi.org/10.1126/science.aaw0911

Brancati, D. (2007). Political Aftershocks: The Impact of Earthquakes on Intrastate Conflict. Journal of Conflict Resolution, 51(5), 715-743. https://doi.org/10.1177/0022002707305234

Brañas-Garza, P., Rodríguez-Lara, I., and Sánchez, A. (2017). Humans expect generosity. Scientific Reports, 7(1), 1-3. https://doi.org/10.1038/srep42446

Calo-Blanco, A., Kováŕík, J., Mengel, F., and Romero, J. G. (2017). Natural disasters and indicators of social cohesion. PLOS ONE, 12(6), e0176885. https://doi.org/10.1371/journal.pone.0176885

Coller, M., and Williams, M. B. (1999). Eliciting individual discount rates. Experimental Economics, 2(2), 107-127. https://doi.org/10.1023/a:1009986005690

Diamond, J. (1997). Guns, Germs and Steel: The Fates of Human Societies (1st ed.). W W Norton and Co Inc.

Diamond, J. M. (2005). Collapse. Viking.

Dietz, T. (2003). The Struggle to Govern the Commons. Science, 302(5652), 1907-1912. https://doi.org/10.1126/science.1091015

Dugatkin, L. A., and Mesterton-Gibbons, M. (1996). Cooperation among unrelated individuals: reciprocal altruism, by-product mutualism and group selection in fishes. Biosystems, 37(1-2), 19-30. https://doi.org/10.1016/0303-2647(95)01542-6.

Eckel, C. C., El-Gamal, M. A., \& Wilson, R. K. (2009). Risk loving after the storm: A BayesianNetwork study of Hurricane Katrina evacuees. Journal of Economic Behavior \& Organization, 69(2), 110-124. 
Engel, C. (2011). Dictator games: a meta study. Experimental Economics, 14(4), 583-610. https://doi.org/10.1007/s10683-011-9283-7

Espín, A. M., Moreno-Herrero, D., Sánchez-Campillo, J., and Rodríguez Martín, J. A. (2018). Do Envy and Compassion Pave the Way to Unhappiness? Social Preferences and Life Satisfaction in a Spanish City. Journal of Happiness Studies, 1-3. https://doi.org/10.1007/s10902-016-98288

Fehr, E., and Schmidt, K. M. (1999). A Theory of Fairness, Competition, and Cooperation. The Quarterly Journal of Economics, 114(3), 817-868. https://doi.org/10.1162/003355399556151

Fehr, Ernst, and Fischbacher, U. (2003). The nature of human altruism. Nature, 425(6960), 785-791. https://doi.org/10.1038/nature02043.

Ferguson, N., Laydon, D., Nedjati Gilani, G., Imai, N., Ainslie, K., Baguelin, M., ... \& Dighe, A. (2020). Report 9: Impact of non-pharmaceutical interventions (NPIs) to reduce COVID19 mortality and healthcare demand.

Frederick, S. (2005). Cognitive Reflection and Decision Making. Journal of Economic Perspectives, 19(4), 25-42. https://doi.org/10.1257/089533005775196732

Gleditsch, N. P. (1998). Armed Conflict and The Environment: A Critique of the Literature. Journal of Peace Research, 35(3), 381-400. https://doi.org/10.1177/0022343398035003007

Griskevicius, V., Tybur, J. M., Delton, A. W., and Robertson, T. E. (2011). The influence of mortality and socioeconomic status on risk and delayed rewards: A life history theory approach. Journal of Personality and Social Psychology, 100(6), 1015-1026. https://doi.org/10.1037/a0022403

Hardin, G. (1968). The Tragedy of the Commons. Science, 162(3859), 1243-1248. https://doi.org/10.1126/science.162.3859.1243

Henrich, J. P., and Henrich, J. P. (2007). Why Humans Cooperate. Oxford University Press.

Holt, C. A., and Laury, S. K. (2002). Risk Aversion and Incentive Effects. The American Economic Review, 92(5), 1644-1655. https://doi.org/10.1257/000282802762024700

Hsiang, S. M., Burke, M., and Miguel, E. (2013). Quantifying the Influence of Climate on Human Conflict. Science, 341(6151), 1235367.

Martin, J., Brañas-Garza, P., Espín, A. M., Gamella, J. and Herrmann, B. (2019). The appropriate response of Spanish Gitanos: Short-run orientation beyond current socio-economic status, Evolution and Human Behavior, 40 (1), 12-22 https://doi.org/10.1016/j.evolhumbehav.2018.07.002

McAdams, D. P., Shiner, R. L., and Tackett, J. L. (2019). Handbook of Personality Development. Guilford Publications.

MSCBS. (2020). Ministerio de Sanidad, Consumo y Bienestar Social - Profesionales - Enfermedad por nuevo coronavirus, COVID-19. mscbs.es. https://www.mscbs.gob.es/profesionales/saludPublica/ccayes/alertasActual/nCovChina/home.htm

Nettle, D., and Saxe, R. (2020). Preferences for redistribution are sensitive to perceived luck, social homogeneity, war and scarcity. Cognition, 198, 104234.

https://doi.org/10.1016/j.cognition.2020.104234 
Ostrom, E. (1990). Governing the Commons. Cambridge University Press.

Ostrom, E., Burger, J., and Field, C. B. (1999). Revisiting the Commons: Local Lessons, Global Challenges. Science, 284(5412), 278-282. https://doi.org/10.1126/science.284.5412.278

Pepper, G. V., and Nettle, D. (2017). The behavioural constellation of deprivation: Causes and consequences. Behavioral and Brain Sciences, 40, 40. https://doi.org/10.1017/s0140525x1600234x

Phan, T. Q., and Airoldi, E. M. (2015). A natural experiment of social network formation and dynamics. Proceedings of the National Academy of Sciences, 112(21), 6595-6600. https://doi.org/10.1073/pnas.1404770112

Rammstedt, B., and John, O. P. (2007). Measuring personality in one minute or less: A 10-item short version of the Big Five Inventory in English and German. Journal of Research in Personality, 41(1), 203-212. https://doi.org/10.1016/j.jrp.2006.02.001

Rand, D. G., and Nowak, M. A. (2013). Human cooperation. Trends in Cognitive Sciences, 17(8), 413-425. https://doi.org/10.1016/j.tics.2013.06.003

Scheffran, J., Brzoska, M., Kominek, J., Link, P. M., and Schilling, J. (2012). Climate Change and Violent Conflict. Science 336(6083), 869-871. https://doi.org/10.1126/science.1221339

Shachat, J., Walker, M. J., \& Wei, L. (2020). The Impact of the Covid-19 Pandemic on Economic Behaviours and Preferences: Experimental Evidence from Wuhan. ESI Working Paper 20-33, https://digitalcommons.chapman.edu/esi_working_papers/328/

Skyrms, B. (2004). The Stag Hunt and the Evolution of Social Structure. Cambridge University Press.

Van Bavel, J.J., Baicker, K., Boggio, P.S. et al. (2020) Using social and behavioural science to support COVID-19 pandemic response. Nature Human Behavior 4, 460-471. https://doi.org/10.1038/s41562-020-0884-z

WHO (2020). Word Health Organization. https://www.who.int/emergencies/diseases/novelcoronavirus-2019.

Weston, D., Hauck, K., \& Amlôt, R. (2018). Infection prevention behaviour and infectious disease modelling: a review of the literature and recommendations for the future. BMC public health, 18(1), 336. 


\section{Appendix: Exposure to the Covid-19 pandemic and generosity}

P. Brañas-Garza ${ }^{1}$, D. Jorrat ${ }^{1}$, A. Alfonso ${ }^{1,2}$, A.M. Espín ${ }^{1,3}$, T. García ${ }^{3}$, J. Kováŕík ${ }^{4,5,6}$

A1. Recruitment

A2. Sample description

A3. Experimental tasks

A4. Further econometric analysis page 2

page 3

page 5

page 9

${ }^{1}$ Loyola Behavioral Lab, Universidad Loyola Andalucía, Spain.

${ }^{2}$ Universidad Pablo de Olavide, Sevilla, Spain.

${ }^{3}$ Universidad de Granada, Spain.

${ }^{4}$ Universidad del País Vasco, Spain.

${ }^{5}$ CERGE-EI, Prague, Czech Republic.

${ }^{6}$ Faculty of Arts, University of West Bohemia, Pilsen, Czech Republic. 


\section{A1. RECRUITMENT}

We invited 103 university students (85 Spaniards, 18 international) from an Andalusian university to recruit participants for our online experiment. Participation was not compulsory (16 students did not participate: 10 national, 6 international). 85 national students recruited other participants from: Andalusia (67), other Spanish regions (4), outside Spain (12), and the remaining 2 decided to discontinue. The remaining 12 international students recruited abroad (not included). They were all students of Game Theory for Social Sciences. This subject is offered to students of Communication, International Relationships, Business Administration, Law and Erasmus/International students. The main purpose of this experiment was to gather data for teaching purposes.

The students were encouraged and incentivized to recruit further participants, with the objective of obtaining a richer subject pool in terms of age, non-student status, and other characteristics. Gender balance and homogeneity across different ages was explicitly encouraged. Students were given between 0 and 100 points for their performance while recruiting participants. 100 points might have an impact of $3 \%$ of their final score ( $\max =30,000$ points).

To study the impact of Covid-19 on behavior was not the goal. However, the home confinement was the reason to run the experiment online in order to have data to discuss in class.

As in any economic experiment, we use monetary incentives. We announce students that we will draw 2 winners from two $100 €$ lotteries. Experimental earnings (from decisions) were converted in tickets for the two $100 €$-lotteries.

After signing the informed consent, they were explicitly asked whether they were aware of the existence of the prize of $100 €$. 96.08\% responded yes. There are no significant differences in donations for responding yes/no to this question (two-sample $t$-test, $p=0.696$ ).

The main variable of this paper refers to the question "If you win the prize of 100€, would like to donate a fraction to an NGO?" This question is incentive compatible. The two winners donated 0 and 20\% respectively. 
The entire experiment additionally included the following tasks: Donations, expected donations, SRsolidarity, SR-envy, the Cognitive Reflection Test (Frederick, 2005, Toplak et al., 2014), Risk Preferences (Holt and Laury, 2002), Time Preferences (Coller and Willians, 1999, Martin et. al., 2019), Stag Hunt Game (Skyrms, 2004) and the Big-5 personality inventory (Rammstedt and John, 2007).

\section{A2. SAMPLE DESCRIPTION}

The experiment was focused on the region of Andalusia, but this did not prevented participation of people from outside Andalusia (people from other parts of Spain, n=191, and from other countries, n=20). Given that the non-Andalusian participants came from many different locations, including 14 Spanish regions and 7 countries, and that their numbers within locations were small and unevenly distributed (across both locations and participation days), they were excluded them from the analyses.

Our sample consists of 969 Andalusian participants who agreed to complete the online survey. Table A1 provides the distribution of participants by day and age category.

\begin{tabular}{|c|c|c|c|}
\hline Day & less than 40 years old & 40 years old or more & Total \\
\hline \multicolumn{4}{|c|}{ Panel A: participants by day } \\
\hline March 20 & 117 & 46 & 163 \\
\hline March 21 & 136 & 52 & 188 \\
\hline March 22 & 82 & 57 & 139 \\
\hline March 23 & 50 & 42 & 92 \\
\hline March 24 & 75 & 54 & 129 \\
\hline March 25 & 149 & 109 & 258 \\
\hline \multicolumn{4}{|c|}{ Panel B: participation by age and day categories } \\
\hline March 20-22 & $335(55 \%)$ & $155(43 \%)$ & $490(51 \%)$ \\
\hline March 23-25 & $274(45 \%)$ & $205(57 \%)$ & $479(49 \%)$ \\
\hline Num. Obs. & 609 & 360 & 969 \\
\hline
\end{tabular}

Table A1. Distribution of participants by day and age category.

Panel A shows that the number of observations is not well distributed over the days. During the first 3 days of the experiment, the participation rate was homogenous (between 14 and 18\% of the total). During the second half, participation rate ranged between $9 \%$ and $27 \%$. Considering the sample according the dates March 23-25 vs. March 20-22, we obtained a balanced sample between both periods 
( $51 \%$ vs $49 \%$ ) and within each age category ( $55 \%$ vs $45 \%$ in the group aged less than 40 years old and $43 \%$ vs $57 \%$ in the group aged 40 or more).

Figure A1 shows the distribution of age over March 20-22 and March 23-25. Both distributions display the same variance (variance ratio t-test, $p>0.30$ ), but their means are significantly different (twosample t-test, $p<0.001)$. Note that we controlled for age in all the regression specifications though.

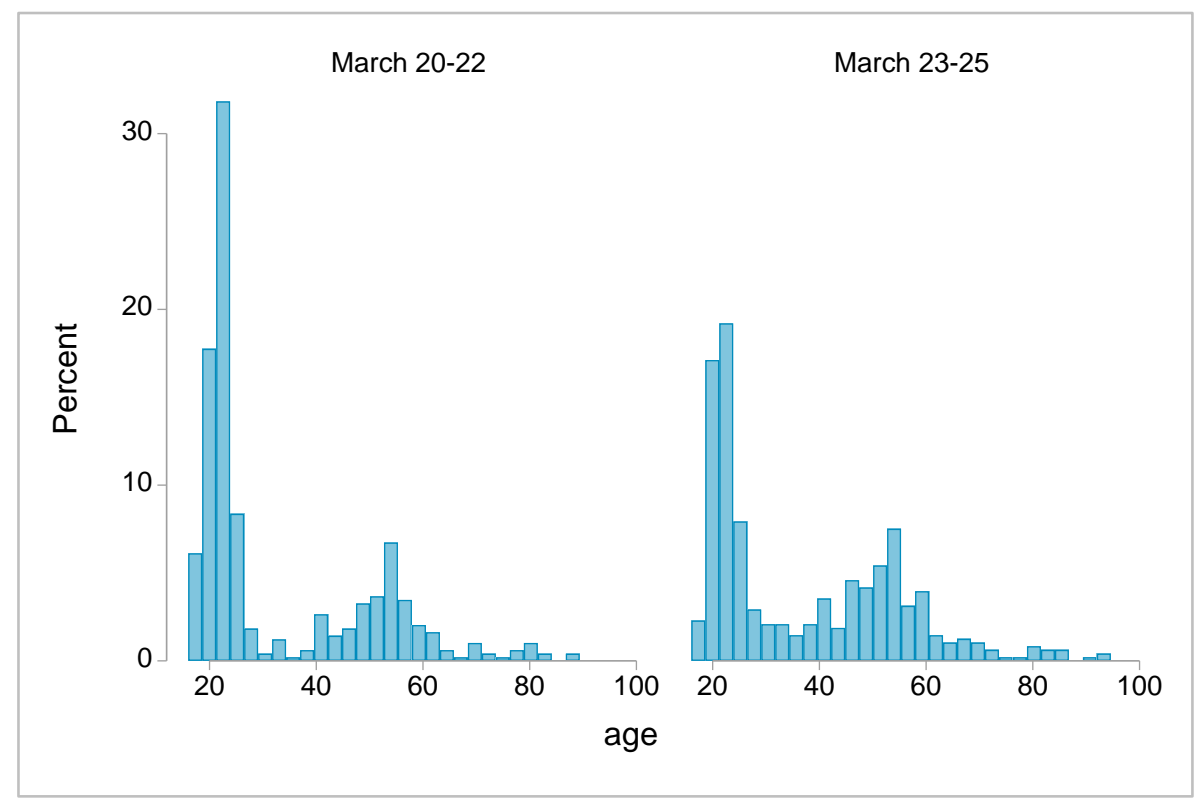

Figure A1. Histogram of age on March 20-22 vs. March 23-25. Left and Right panels display the distribution of ages in March 20-22 and March 23-25, respectively.

Regarding gender distribution, 55\% of our sample were females: 56\% in March 20-22, 54\% in March 23-25. Education was a categorical variable that ranged between 1 and 8, representing different education categories: (1) complete secondary school, (2) incomplete high-school (3) complete highschool, (4) incomplete vocational training, (5) complete vocational training, (6) incomplete university degree, (7) complete university degree, (8) postgraduate. The first mode of this variable was category 6 and the second mode was category 7. The mean was $5.43(S D=1.91)$ and $5.53(S D=1.97)$ in March 20-22 and 23-25, respectively. The difference is not statistically different from zero (two-sample $t$-test, $p=0.397)$ 


\section{A3. EXPERIMENTAL TASKS}

\section{Actual donations}

Figure A2 compares the distribution of donations in our data with the results of the meta-analysis conducted by Engel (2011). Panel A reproduces the histogram of giving to "deserving recipients" that included donations to charities in Engel (2011; Figure 4, right panel, page 94). Panel B shows the distribution of donations in the first half of our experiment (March 20-22). Panels A and B are structurally similar, although participants in our experiment are somehow less generous and the modal donation is $0 \%$ in our data, rather than $100 \%$ as in Engel (2011). Panel C illustrates the donations during the second half of our experiment (March 23-25). Note that the distribution shifts to the left in March 23-25, indicating that the exposure to Covid-19 may have a negative impact on giving.

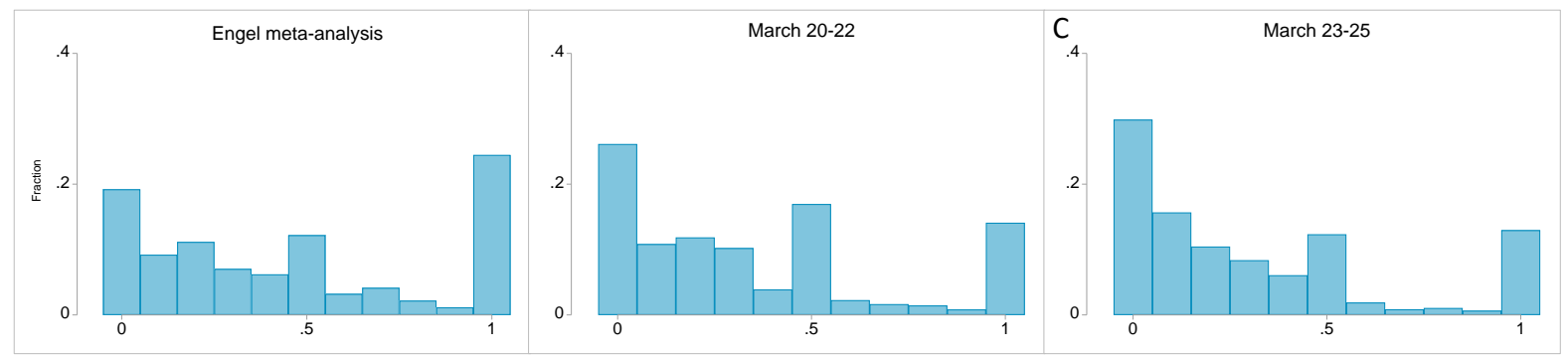

Figure A2. Comparing our data with Engel (2011). Panel A corresponds to the data of Engel (2011) for donations to deserving recipients, including charities (Figure 4, page 94). Panel B shows our aggregate data of donations for March 20-22. Panel C displays our data for days March 23-25.

Our main outcome variable is actual donations, where participants had to decide what fraction the $100 €$ prize wish to donate to an NGO. Thus, donation is set as a continuous variable ranging from 0 to 1 . Figure A3 plots the distribution and the average (dashed vertical line) of donations in March 20-22 (panels A and B) and March 23-25 (panels C and D). The figure shows the data broken down by age groups (panels A and C) and gender (panels B and D). The average donation in March 20-22 was 0.46 $(S D=0.38)$ among participants aged 40 years old or more and $0.30(S D=0.30)$ among participants with less than 40 years old. In March 23-25, these averages were, respectively, $0.35(S D=0.35)$ and $0.29(S D=0.33)$. Splitting by gender, the average donation in March $20-22$ was $0.35(S D=0.32)$ for 
females and $0.35(S D=0.36)$ for males. In March 23-25, the averages for females and males were 0.30 $(S D=0.31)$ and $0.31(S D=0.36)$, respectively.

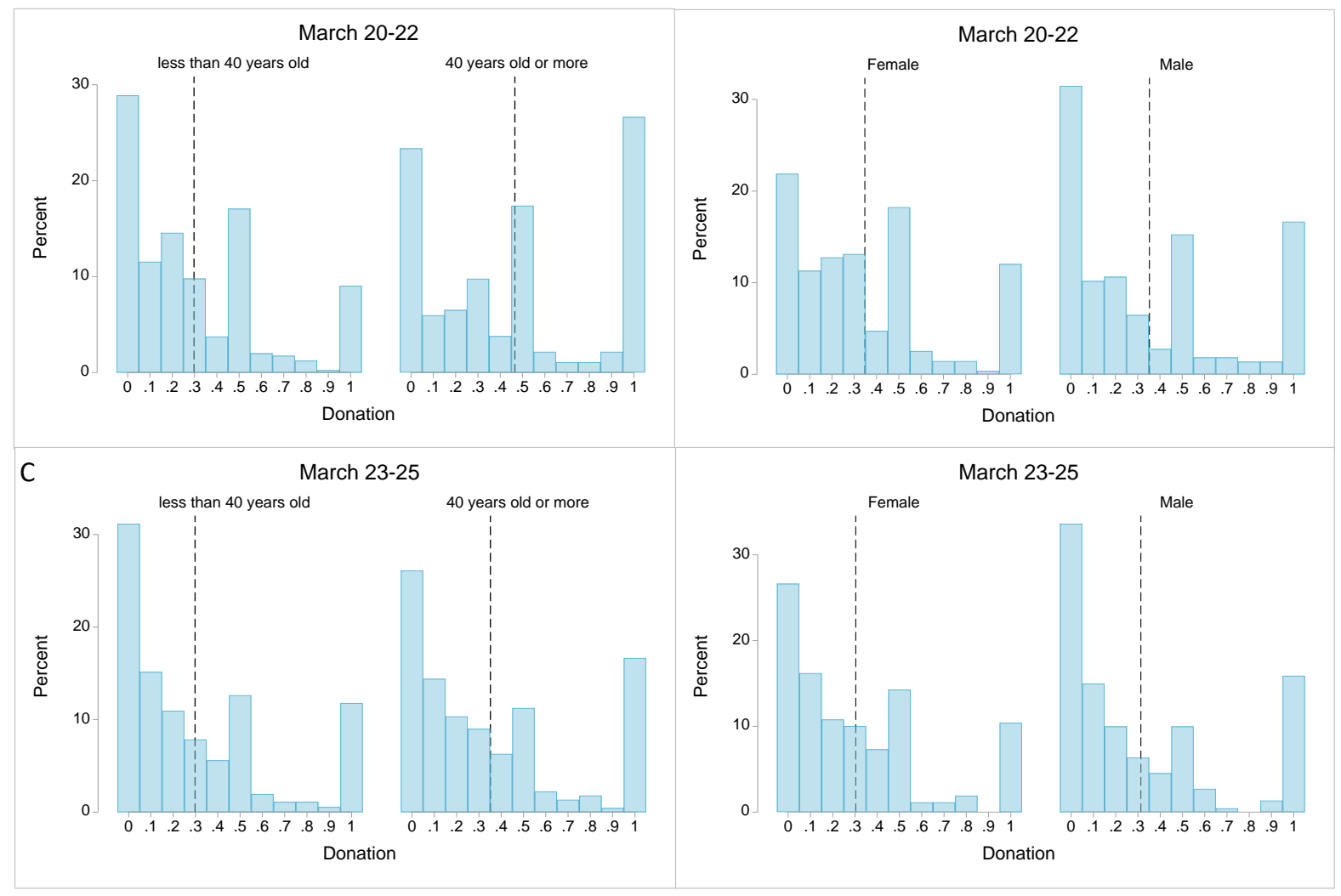

Figure A3. Actual donations on March 20-22 (A and B) vs. March 23-25 (C and D). Panels (A) and (C) display the distribution of donations by age groups ( $<40$ years old and $\geq 40$ years old) for Mar 20-22 and 23-25, respectively. Panels B and D display the distribution of donations by gender for Mar 20-22 and 23-25, respectively. Dashed vertical lines represent the average donation in each panel.

\section{Expected donations}

After making their donation decision, we asked participants to report their beliefs about other participants' donations. Using the same format as actual donations, they reported their answers to the question "How much money do you think the other participants will donate to the NGO?”. The variable “expected donation” thus also ranges from 0 to 1 in 0.1 increments.

Figure A4 plots the distribution and the average (dashed vertical line) of the expected donations broken down by participation day (March 20-22 vs March 23-25). The average expected donation was 0.27 $(S D=0.25)$ in March 20-22 and $0.25(S D=0.25)$ in March 23-25. 


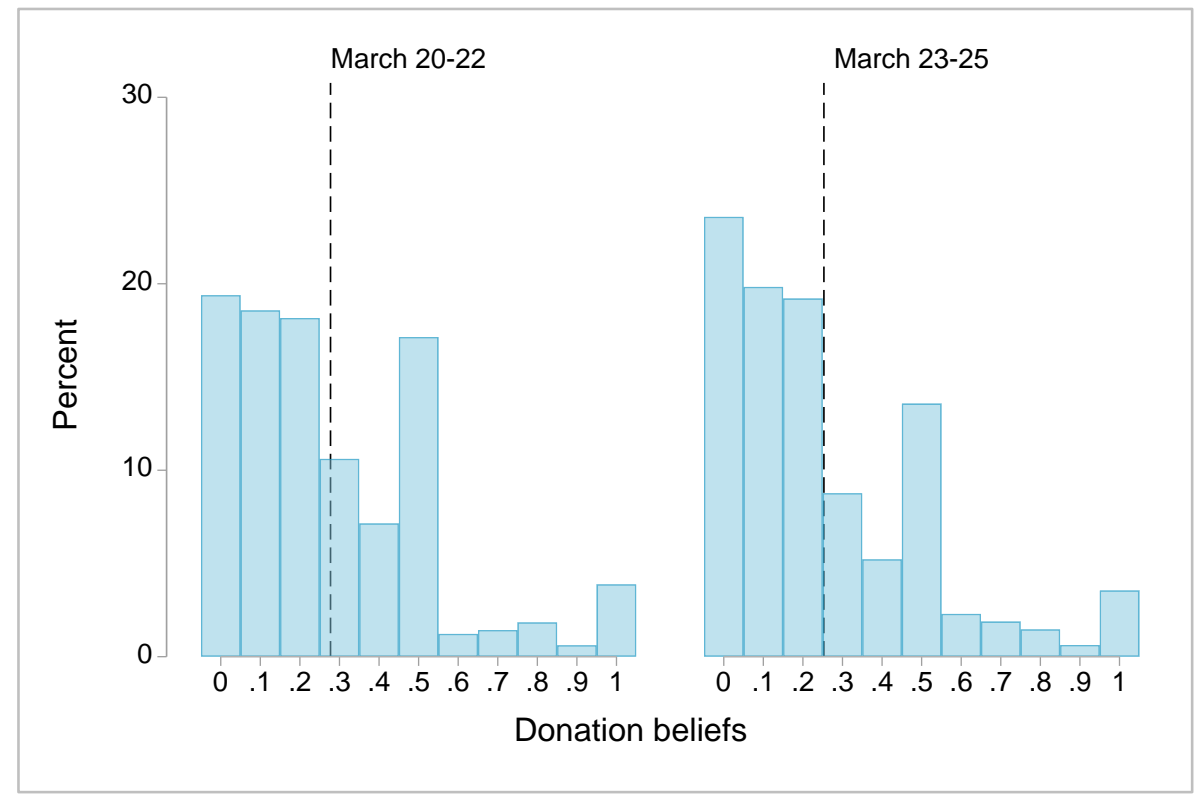

Figure A4. Expected donations on March 20-22 vs. March 23-25. Dashed vertical lines represent the average in each subsample.

\section{Self-reported solidarity}

This variable refers to people’s aversion to advantageous inequality (Fehr and Schmidt 1999), often also referred to as “compassion” or "guilt”. Using a Likert scale, we asked participants their agreement with the statement "I'm do not care about how much money I have; what concerns me is that there are people who have less money than I have.” (Espín et al. 2018).

The participants answered either on a 1-7 scale (63.7\% of the final sample) or on a 1-10 scale (36.3\%), where 1 refers to "strongly disagree" and 7 (or 10) refers to "strongly agree”. To normalize the different values of this variable to the $0-1$ scale we employed the standard min-max method. The mean and $S D$ of this normalized variable are 0.48 and 0.31 , respectively, and show no significant difference by scale subsample (i.e. $1-7$ vs 1-10; two-sample t-test, $p>0.40$, variance ratio test, $p>0.1$ ). Also, the two subsamples display the same rank distribution (Mann-Whitney test, $p>0.2$ ). Figure A5 plots the distribution of the normalized solidarity variable (labeled as SR-solidarity) for March 20-22 (mean $=0.46, S D=0.31)$ and March 25-25 (mean $=0.50, S D=0.31)$ separately. 


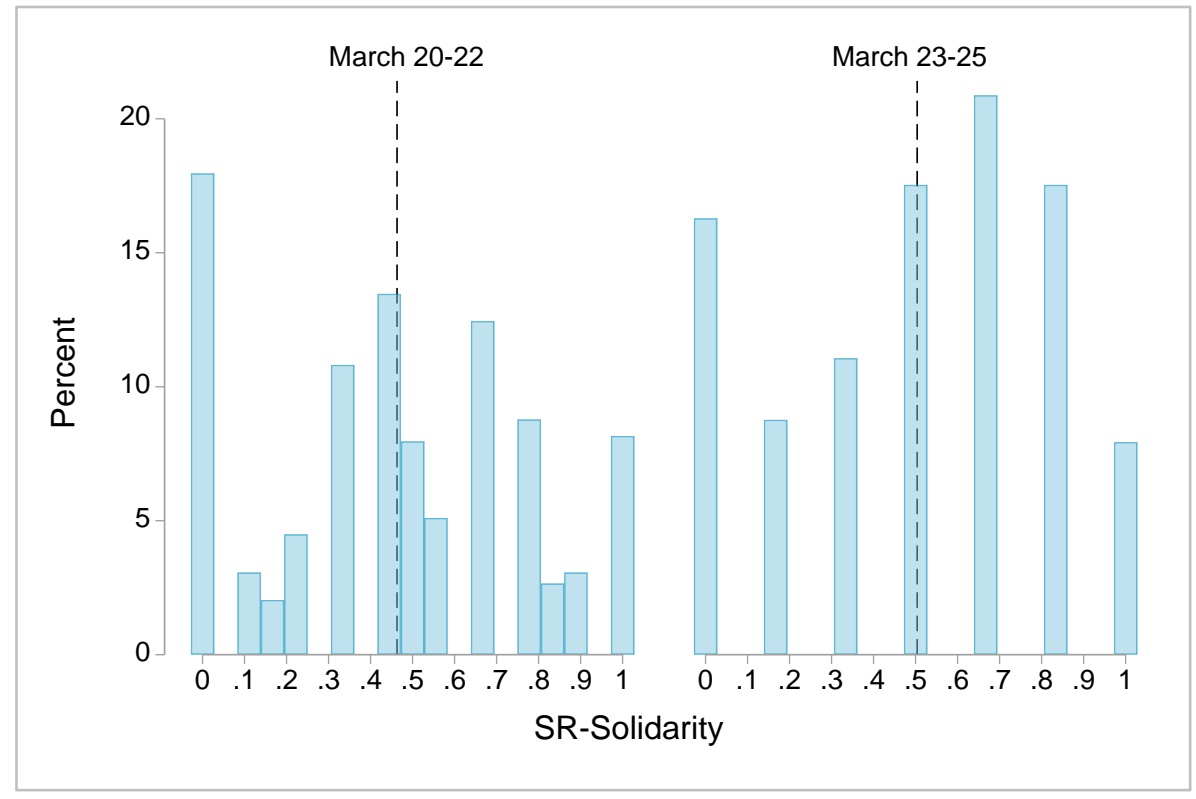

Figure A5. SR-solidarity on March 20-22 vs. March 23-25. Dashed vertical lines represent the average in each subsample.

\section{Self-reported envy}

Figure A6 refers to people's aversion to disadvantageous inequality. In this question participants reported their agreement with the statement "I'm do not care about how much money I have; what concerns me is that there are people who have more money than I have".

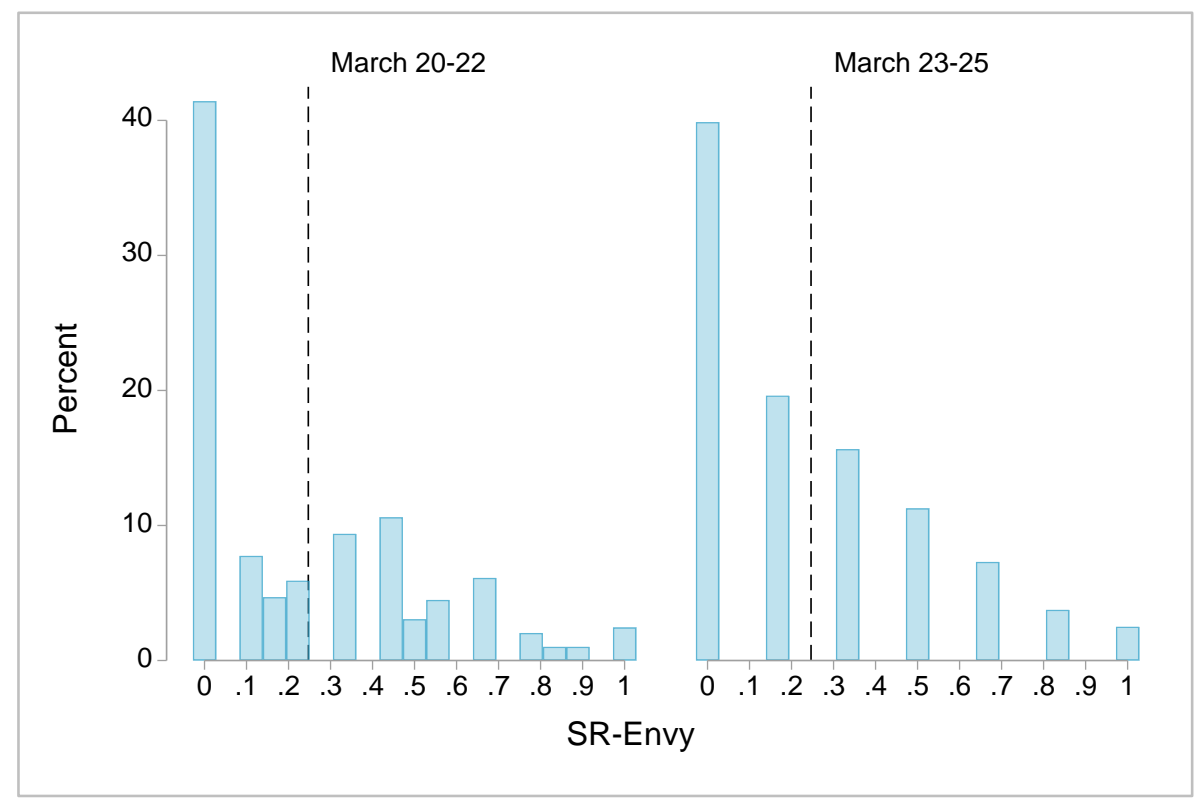

Figure A6. SR-envy on March 20-22 vs. March 23-25. Dashed vertical lines represent the average in each subsample. 
SR-envy was asked after SR-solidarity, as in Espín et al. (2018), and we used an identical design: the same subsamples answered on either a 1-7 or 1-10 scale. Again, this variable was normalized and the mean (0.25 in the total sample), $S D$ (0.27 in the total sample) and distribution do not differ in the two subsamples (t-test, $p>0.6$; variance ratio test, $p>0.4$ and Mann-Whitney test, $p>0.5$ ). Figure A6 plots the distribution of the normalized envy variable (labeled as SR-envy) for March 20-22 (mean $=0.25$, $S D=0.28)$ and March 25-25 (mean $=0.25, S D=0.27$ ) separately.

\section{A4. FURTHER ECONOMETRIC ANALYSIS}

\begin{tabular}{|c|c|c|c|c|c|c|}
\hline & $\begin{array}{c}1 \mathrm{a} \\
\text { Donation }\end{array}$ & $\begin{array}{c}1 \mathrm{~b} \\
\text { Donation }\end{array}$ & $\begin{array}{c}1 \mathrm{c} \\
\text { Donation }\end{array}$ & $\begin{array}{c}2 \mathrm{a} \\
\text { Donation }\end{array}$ & $\begin{array}{c}2 \mathrm{~b} \\
\text { Donation }\end{array}$ & $\begin{array}{c}2 \mathrm{c} \\
\text { Donation }\end{array}$ \\
\hline mar23-25 & $\begin{array}{c}-0.032^{*} \\
(0.017)\end{array}$ & $\begin{array}{c}0.185 \\
(0.134)\end{array}$ & $\begin{array}{c}0.086 \\
(0.163)\end{array}$ & $\begin{array}{c}-0.066^{* * *} \\
(0.021)\end{array}$ & $\begin{array}{c}0.229 \\
(0.165)\end{array}$ & $\begin{array}{c}0.114 \\
(0.210)\end{array}$ \\
\hline male & $\begin{array}{c}0.011 \\
(0.017)\end{array}$ & $\begin{array}{c}-0.008 \\
(0.024)\end{array}$ & $\begin{array}{l}-0.111 \\
(0.204)\end{array}$ & $\begin{array}{c}0.016 \\
(0.021)\end{array}$ & $\begin{array}{c}0.015 \\
(0.030)\end{array}$ & $\begin{array}{c}-0.018 \\
(0.234)\end{array}$ \\
\hline 1(age) & $\begin{array}{c}0.076 * * * \\
(0.020)\end{array}$ & $\begin{array}{c}0.110^{* * * *} \\
(0.031)\end{array}$ & $\begin{array}{c}0.096 * * \\
(0.039)\end{array}$ & $\begin{array}{c}0.119 * * * \\
(0.025)\end{array}$ & $\begin{array}{c}0.163 * * * \\
(0.036)\end{array}$ & $\begin{array}{c}0.159 * * * \\
(0.048)\end{array}$ \\
\hline mar23-25 × 1(age) & & $\begin{array}{c}-0.068^{*} \\
(0.039)\end{array}$ & $\begin{array}{c}-0.039 \\
(0.048)\end{array}$ & & $\begin{array}{c}-0.086^{*} \\
(0.049)\end{array}$ & $\begin{array}{c}-0.061 \\
(0.062)\end{array}$ \\
\hline mar23-25 $\times$ male & & $\begin{array}{c}0.038 \\
(0.034)\end{array}$ & $\begin{array}{c}0.260 \\
(0.277)\end{array}$ & & $\begin{array}{c}0.002 \\
(0.043)\end{array}$ & $\begin{array}{c}0.190 \\
(0.336)\end{array}$ \\
\hline male $\times 1($ age $)$ & & & $\begin{array}{c}0.031 \\
(0.061)\end{array}$ & & & $\begin{array}{c}0.010 \\
(0.071)\end{array}$ \\
\hline mar23-25 $\times 1($ age $) \times$ male & & & $\begin{array}{c}-0.064 \\
(0.081)\end{array}$ & & & $\begin{array}{c}-0.054 \\
(0.097)\end{array}$ \\
\hline expected donations & $\begin{array}{c}0.830 * * * \\
(0.037)\end{array}$ & $\begin{array}{c}0.829 * * * \\
(0.037)\end{array}$ & $\begin{array}{c}0.829 * * * \\
(0.037)\end{array}$ & & & \\
\hline SR-Solidarity & & & & $\begin{array}{c}0.196 * * * \\
(0.037)\end{array}$ & $\begin{array}{c}0.193 * * * \\
(0.037)\end{array}$ & $\begin{array}{c}0.192 * * * \\
(0.037)\end{array}$ \\
\hline SR-Envy & & & & $\begin{array}{c}-0.124 * * * \\
(0.038)\end{array}$ & $\begin{array}{c}-0.123 * * * \\
(0.038)\end{array}$ & $\begin{array}{c}-0.123 * * * \\
(0.038)\end{array}$ \\
\hline Constant & $\begin{array}{c}-0.141^{* *} \\
(0.065)\end{array}$ & $\begin{array}{c}-0.248^{* *} \\
(0.100)\end{array}$ & $\begin{array}{c}-0.204 \\
(0.127)\end{array}$ & $\begin{array}{c}-0.122 \\
(0.080)\end{array}$ & $\begin{array}{c}-0.267 * * * \\
(0.114)\end{array}$ & $\begin{array}{c}-0.253^{* * *} \\
(0.151)\end{array}$ \\
\hline Observations & 969 & 969 & 969 & 969 & 969 & 969 \\
\hline Adjusted R-squared & 0.414 & 0.415 & 0.414 & 0.081 & 0.082 & 0.081 \\
\hline Province FE & No & No & No & No & No & No \\
\hline F test & $148.10 * * *$ & $98.21 * * *$ & $74.34 * * *$ & $8.42 * * *$ & $7.61 * * *$ & $6.91 * * *$ \\
\hline
\end{tabular}

Table A2. OLS estimates: the impact of Covid-19 exposure on actual donations. The variable mar2325 represents the increasing exposure to the Covid-19 threat as a dummy variable taking the value of 1 if the participation was during March 23 to March 25 and 0 if it was during March 20 to March 22. All regressions include a male dummy variable and age in logs. 


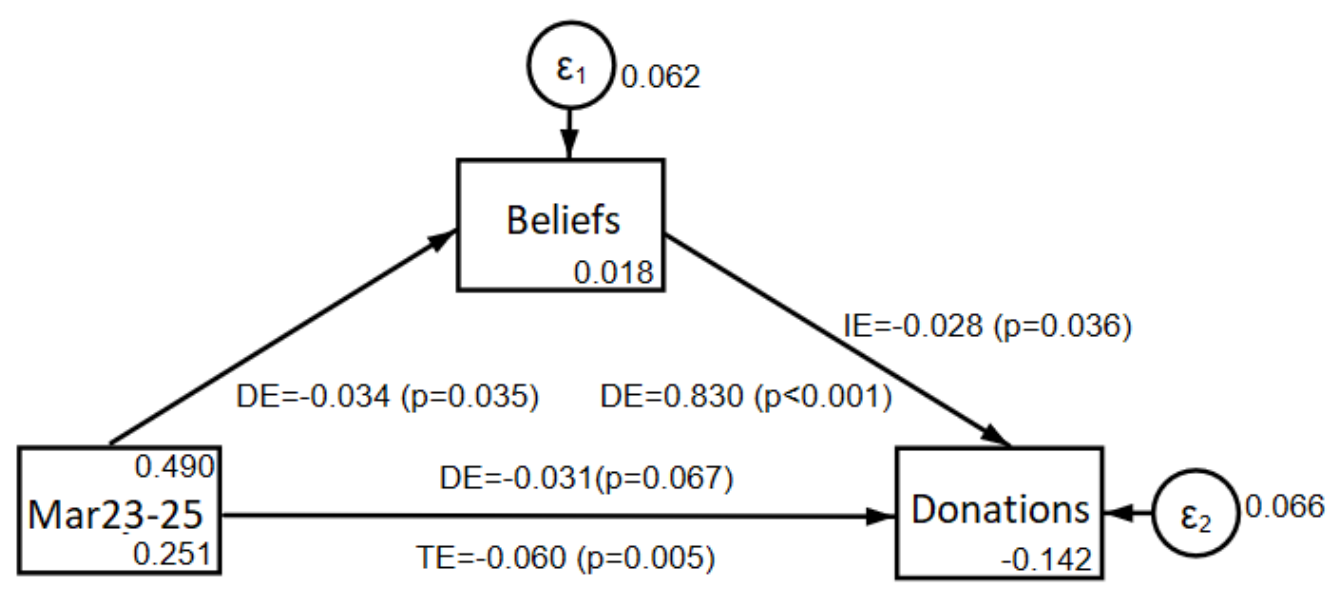

Figure A7. Mediation analysis. We display the output of the mediation analysis for the model using the basic specification in Table A1. The coefficients displayed correspond to: the direct effects (DE) for participation day on donation beliefs, and for both variables on donations; the total effect (TE) of participation day on donations; and the indirect effect (IE) of participation day on donations, as mediated by donation beliefs. 

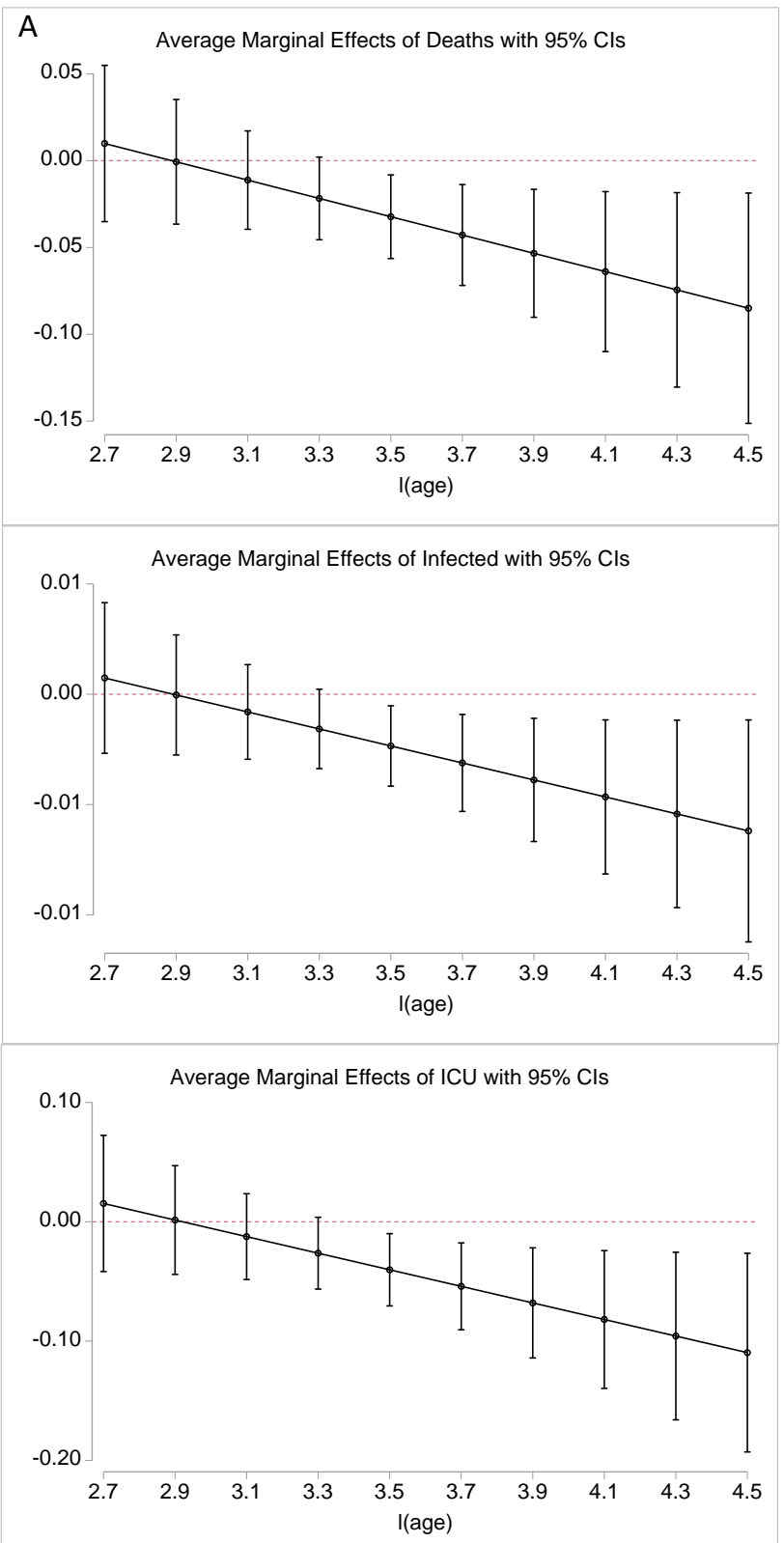

Figure A8. Average marginal effects on predicted donations. Panel (A) refers to number of deaths, panel (B) to infected people and (C) to patients at ICU. Error bars represent $95 \%$ CI. 